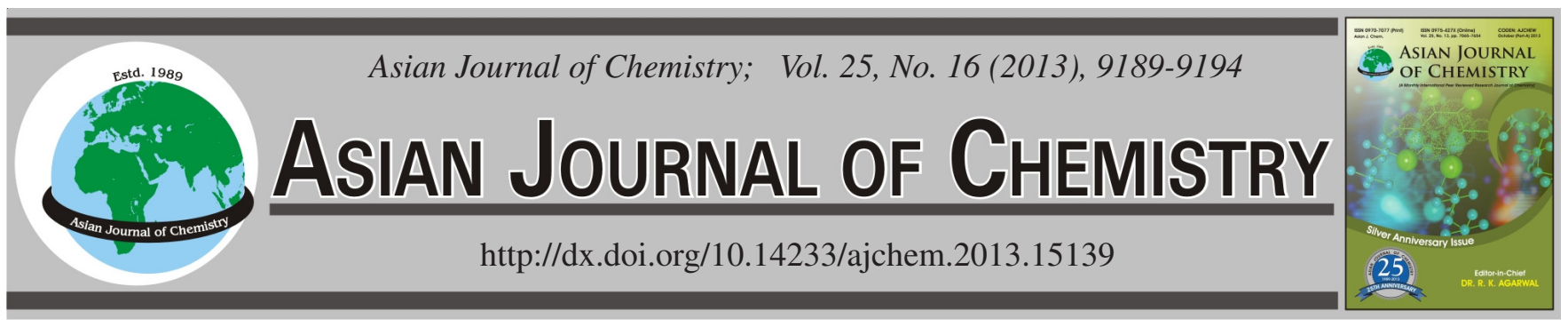

\title{
Determination of Oxidized Triacylglycerol Polymers by Preparative Flash Chromatography and High-Performance Size-Exclusion Chromatography
}

\author{
W.M. CAO ${ }^{1,2, *}$, K.Y. ZHANG ${ }^{1}$, B. XUE ${ }^{2}$, F.X. CHEN ${ }^{2}$, Q.Z. JIN ${ }^{1}$ and X.G. WANG ${ }^{1, *}$
}

${ }^{1}$ State Key Laboratory of Food Science and Technology, School of Food Science and Technology, Jiangnan University, 1800 Lihu Avenue, Wuxi 214122, P.R. China

${ }^{2}$ Shanghai Grain Science Research Institute, No. 2, 955 Jujiaqiao Road, Shanghai 200136, P.R. China

*Corresponding author: E-mail: wmcaosh@sohu.com; wxg1002@hotmail.com; kangyilixia@hotmail.com

(Received: 14 January 2013;

Accepted: 20 September 2013)

AJC-14142

\begin{abstract}
Polar compounds were obtained by preparative flash chromatography (PFC). Oxidized triacylglycerol oligomers (TGO), oxidized triacylglycerol dimers (TGD), oxidized triacylglycerol monomers (ox-TGM), diacylglycerols (DG) and free fatty acids in oil were separated through high-performance size-exclusion chromatography (HPSEC). A pool of mixed TGP standard samples was used to check linearity, limit of detection (LOD, $S / N \geq 3$ ) and limit of quantification (LOQ, $S / N \geq 10$ ). The calibration curves for TGO and TGD were linear in the range of $28-1800$ and $11-2800 \mathrm{mg} / \mathrm{L}$ with coefficients $\left(\mathrm{r}^{2}\right)$ greater than 0.99 , respectively. The LOD and LOQ were 28 and $1800 \mathrm{mg} / \mathrm{L} \mathrm{for}$ TGO, 11 and $2800 \mathrm{mg} / \mathrm{L}$ for TGD. The LOD is $0.01 \%$ for TGP. The repeatable relative standard deviations (RSDs) of TGP was less than $10 \%$. Three concentrations of polar compounds-spiked samples were separated by PFC with recoveries ranging from 95.4-97.7 \% with RSDs less than $4 \%$. PFC-HPSEC matched traditional silica column well. TGP determination was completed within $2 \mathrm{~h}$.
\end{abstract}

Key Words: Oxidized triacylglycerol polymers, Preparative flash chromatography, Gel permeating chromatography.

\section{INTRODUCTION}

The defeat of oil at high temperature mainly involves the hydrolysis, oxidation and thermal alteration ${ }^{1}$. The polar compounds (PC) produced in the process of edible oil deterioration possess higher polar than that of normal vegetable oil molecules-triacylglycerol. Generally, the polar compounds include thermal oxidation products (containing ketone, aldehyde, hydroxyl, peroxide-based hydrogen and carboxyl), thermal polymers products, thermal oxidation polymerization products and hydrolysis products (free fatty acids (FFA), monoacylglycerol and diacylglycerol (DG)) of triacylglycerol ${ }^{2}$. The oxidized triacylglycerol monomers (ox-TGM), oxidized triacylglycerol polymers (TGP) and diacylglycerols (DG) in oil polar compounds represent the degree of oil oxidation, polymerization and hydrolysis, respectively. The determination of oil TGP was employed widely in research not only on the frying oils field ${ }^{3,4}$, but also for the oil oxidation ${ }^{5,6}$, the quality control of refined oil ${ }^{7,8}$, the identification of virgin oil and the identification of kitchen waste oil ${ }^{9,10}$.

The ISO and AOCS methods are standard methods for determination of TGP content in oils ${ }^{11,12}$. With these methods, the oil sample are directly used for high-performance size- exclusion chromatography (HPSEC) analysis. The typical chromatographic peaks according to the order of molecular weight are followed by five peaks of TGO, TGD, ox-TGM, DG, FFA and other unsaponifiable compounds, etc. The component proportion was quantified with area normalization method. The methods are suitable for the animal and vegetable oils of which content of TGP is higher than $3 \%$, but they are not appropriate for the analysis of refined edible vegetable oils of relatively lower content of TGP. In addition to that, the method couldn't distinguish between the polar oil oxidation polymers and non-polar thermal polymers.

In order to improve the detection sensitivity and accurately determine TGP in oils, many modified methods were employed including silica gel column-HPSEC ${ }^{13-15}$, small silica gel column-HPSEC ${ }^{16}$, solid phase extraction-HPSEC methods ${ }^{17}$ etc. However, all assays increased the pre-separation of polar compounds in oils before HPSEC ${ }^{18}$. Typical silica gel columnHPSEC and small silica gel column-HPSEC method were operated fussily. Silica gel column required high manual loading technology. Air bubbles and cracks easily appear in cylinder. The flow rate control of mobile phase was not easily uniform. Solvent and filler required much material and time. Small silica gel column-HPSEC and solid phase extraction- 
HPSEC methods require the reduced amounts of sample and supplies. Compared with the classic method ${ }^{14}$, the standard deviation would become bigger when the small silica gel column-HPSEC method was used for the analysis of low levels of TGP and the solid phase extraction-HPSEC for the analysis of high levels of TGP in oils, respectively ${ }^{18}$. Besides that, the solid-phase extraction-HPSEC method required the expensive stearic monoglyceride as internal standard for the analysis of oil samples.

This study aims mainly to develop a novel method for determination of TGP content in edible oils. This method exhibits several characteristics such as operation-convenient, internal standard free, quantitative range wide and high sensitive, which is suitable for frying oil, refined oil and various other oils with changed structure and texture. This method employed standard operating preparative rapid column chromatography system and preparative fast FLASH column to pre-separate the polar components and non-polar components of oil samples and then determine the polar compounds content with weight method. This method subdivided polar compounds via HPSEC system into TGO, TGD, ox-TGM, DG, FFA and other components. TGP (TGO + TGD) of oil was quantified with area normalization method.

\section{EXPERIMENTAL}

CHEETAH MP200 Preparative Flash Chromatography System (Tianjin Bernard Agela technology companies), Preparative Flash Chromatographic Column, Agela Flash Column Silica-CS (silica gel: $20 \mathrm{~g}$, grain diameter: 40-60 $\mu \mathrm{m}$, aperture: $6 \mathrm{~nm}$ ), R204B Rotavapor, Waters 2695 high performance liquid chromatographic analyzer, 2414 differential refractive index detector (RI) and Styragel HR 0.5 volume exclusion gel column chromatography $(\varphi 7.8 \mathrm{~mm} \times 300 \mathrm{~mm}$, grain diameter $5 \mu \mathrm{m}$, aperture $10 \mathrm{~nm}$, Waters company) were used to carried out the analysis.

Tetrahydrofuran (THF, chromatography grade), diethyl ether (analytical reagent), petroleum ether (analytical reagent, boiling range: $30-60{ }^{\circ} \mathrm{C}$ ), SL-105 relative standard molecular weight suit (Shodex company).

Polarity content standard sample: the sample was prepared from the Fried oil samples (including $25 \%$ polar compounds, polar compounds contains $18 \%$ of TGO and $28 \%$ of TGD) according to AOCS Cd20-91 and IUPAC 2.508 method.

Edible vegetable oil samples: First grade bean oil, first grade squeezing corn oil, extra virgin olive oil, first grade squeezing sunflower seed oil, yang rice oil and cold pressing sesame were purchased from major supermarkets in Shanghai.

Refined kitchen waste oil samples were from the "ditch oils" sample library collected by Shanghai Institute of Food Science. The unknown "ditch oil" sample (National Ministry of Health).

General procedure and detection method: The aforementioned polarity standard samples $(100 \mathrm{mg})$ were dissolved in $\mathrm{THF}(10 \mathrm{~mL})$ as the polarity standard mother liquor, in which the concentration of TGP was $4600 \mathrm{mg} / \mathrm{L}$ (TGO was 1800 $\mathrm{mg} / \mathrm{L}$, TGD was $2800 \mathrm{mg} / \mathrm{L}$ ). Then this mother liquor was diluted continuously to be 10 standard liquid sample and the concentration of TGP was 4600, 2300, 1150, 575, 287, 144,
72, 36, 18 and $9 \mathrm{mg} / \mathrm{L}$, respectively.These standard liquid samples were used in HPSEC to investigate the linear range, lowest detection limit and quantitative lower limit.

Then the content of polar compounds in cold pressing sesame oil ( $1 \mathrm{~g}$ ) was determined as the background value according to AOCS Cd20-91 method. 25, 100 and $400 \mu \mathrm{L}$ of polarity standard samples were added into the cold pressing sesame oil by microinjector as three concentration level of standard addition oil samples. Each added concentration level of samples was prepared in pairs to examine the recovery of PC from oil by flash column chromatography method.

According to AOCS Cd20-91 method, the eluent for polar compounds was ethyl ether $(25 \mathrm{~mL})$ and the eluent for non-polar material was miscible liquids $(25 \mathrm{~mL}$, petroleum ether/ethyl ether $=87 / 13$ ). The solvent of collecting polar compounds eluent was dried by atmospheric pressure rotating evaporation at $60{ }^{\circ} \mathrm{C}$. Then it was put in the vacuum drying oven for $0.5 \mathrm{~h}$ at $40^{\circ} \mathrm{C}$. The samples were tested via thin layer chromatography (TLC) and the results revealed that it didn't contain non-polar components. The nonpolarity of components obtained as the same way was used in HPSEC to verify the separation result.

Two preparation flash column chromatography were serried. The washing liquid (petroleum ether/ethyl ether $=87 / 13$ ) flushed the balanced serried Flash columns with a rate of 25 $\mathrm{mL} / \mathrm{min}$ for $10 \mathrm{~min}$. Oil samples $(1.0 \mathrm{~g})$ dissolved in petroleum ether $(5 \mathrm{~mL})$ were injected in a syringe $(10 \mathrm{~mL})$, washed, eluted and collected with a flow rate of $23-25 \mathrm{~mL} / \mathrm{min}$ according to Table-1. The wavelength of ultraviolet detector was $200 \mathrm{~nm}$.

\begin{tabular}{cccc}
\multicolumn{4}{c}{ TABLE-1 } \\
& \multicolumn{2}{c}{ ELUTION AND COLLECTION PROCEDURES } \\
& OF PREPARATIVE FLASH CHROMATOGRAPHY \\
\hline Entry & Solvent & Time (min) & Collections \\
\hline 1 & $\begin{array}{c}\text { Petroleum ether:ethyl } \\
\text { ether }=87: 13\end{array}$ & $1-19$ & $\begin{array}{c}\text { Nonpolar } \\
\text { compounds }\end{array}$ \\
2 & $\begin{array}{c}\text { Petroleum ether : ethyl } \\
\text { ether }=87: 13\end{array}$ & $20-25$ & $\begin{array}{c}\text { Polar compounds } \\
\text { Ethyl ether }\end{array}$ \\
3 & $26-50$ & Polar compounds \\
\hline
\end{tabular}

Polar or non-polar components were separated, dissolved in THF $(100 \mathrm{~mL})$ and filtrated with membrane $(0.22 \mu \mathrm{m})$. Styragel gel chromatography protect column, Styragel HR 0.5 size-exclusion gel chromatography column (double column in series), the volume of injected sample $(10 \mu \mathrm{L})$, velocity $(0.7 \mathrm{~mL} / \mathrm{min})$, column temperature $\left(35^{\circ} \mathrm{C}\right)$, mobile phase (THF), differential refractive detector, the testing pool temperature $\left(35^{\circ} \mathrm{C}\right), \mathrm{SL}-105$ polystyrene standard relative molecular weight for qualitative analysis, peak area normalization method for quantitative analysis.

According to the method of IUPAC 2.507, the effect of oil polar compounds which was separated by adsorption chromatography or preparative fast column chromatography was validated via thin layer chromatography board (The $200 \mathrm{~mm}$ length, $100 \mathrm{~mm}$ width of glass was smeared by the Merck silica gel 60 whose thickness was $0.25 \mathrm{~mm}$ ).

The non-polar compounds obtained $(0.1 \mathrm{~g})$ were dissolved in THF $(10 \mathrm{~mL})$ as injected liquid. The liquid $(10 \mu \mathrm{L})$ was filtrated by membrane $(0.22 \mu \mathrm{m})$, injected and analyzed through HPSEC method in "2.5" chromatographic conditions. 
The purpose was to validate the separation result of oil nonpolar compounds separated via preparative fast column chromatography method.

\section{RESULTS AND DISCUSSION}

The oil polar compounds and non-polar compounds were separated so that they were under real-time monitored. The typical chromatography pattern was shown in Fig. 1a. The separated polar compounds was analyzed. The obtained HPSEC chromatogram and retention time were shown in Fig. 1b. TGO, TGD, ox-TGM, DG, FFA, etc., appeared consequently according to the order of molecular weight. The last peak even included the polarity of unsaponifiable matter. The consuming time for separating and concentrating polar compounds was $1.5 \mathrm{~h}$ through Preparative fast column chromatography, while the time was $0.5 \mathrm{~h}$ when using HPSEC. The parameters used in the entire analytic process were program controlled. The operation is simple and its standardization is easy.

(a)

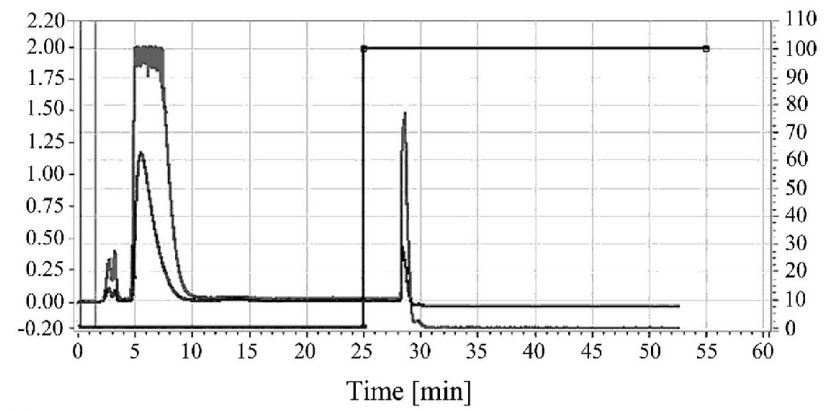

(b)

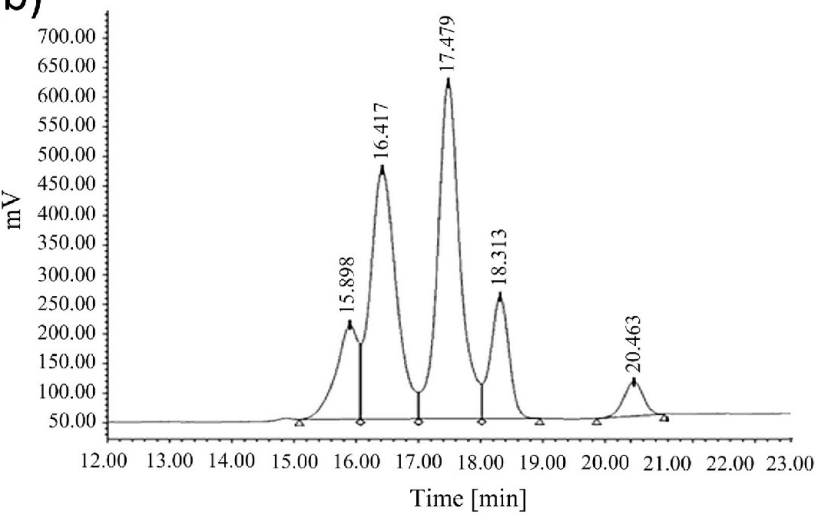

(c)

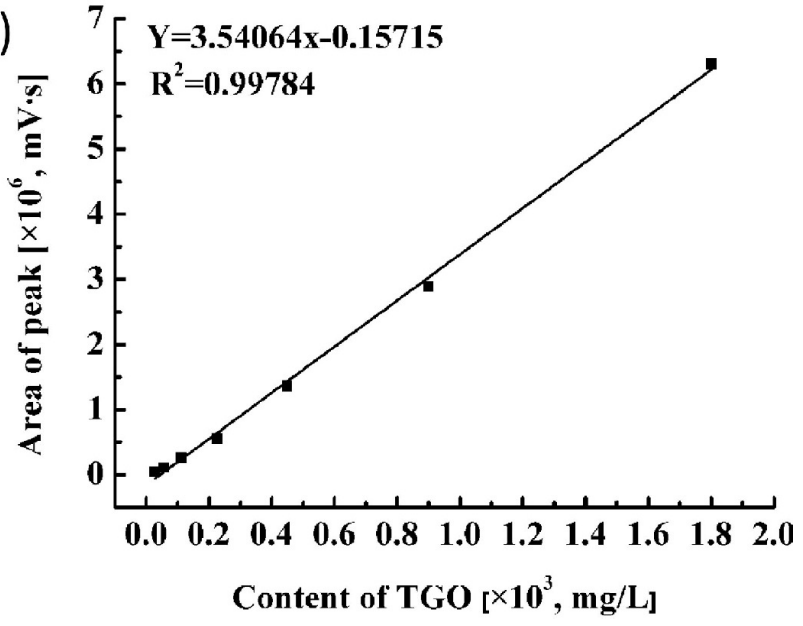

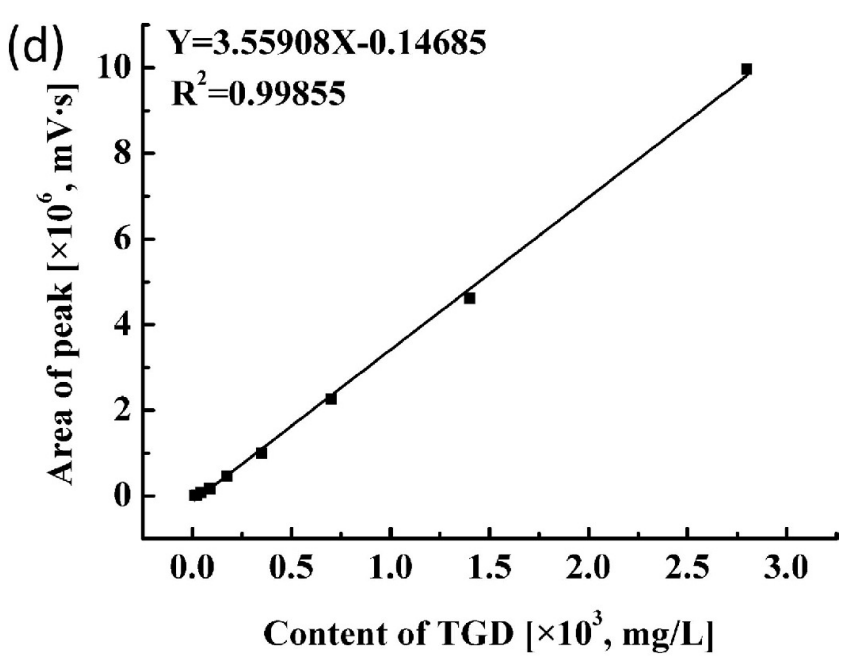

Fig. 1. (a) Representative chromatogram of preparative flash chromatography. Nonpolar compounds: 0-19 min, polar compounds: 20-50 min. (b) Representative chromatograms of polar compounds separation by PFC-HPSEC. Retention time ( $\min$ ): 15.90 and 16.42, polymerized triacylglycerols; 17.48 , oxidized triacylglycerols; 18.31, diacylglycerols and 20.46, fatty acids and polar unsaponifiable fraction. (c) Linear regression between concentration of TGO and its response in HPSEC. (d) Linear regression between concentration of TGD and its response in HPSEC

Ten mixed TGP standard solution with various dilution degrees were determined by HPSEC. As shown in Fig. 1c,d, the standard curve was drawn based on the corresponding relationship between the peak area of target components TGO or TGD and the mass concentration ratio (x, mg/L). TGO had a good linear relationship in the range of $28-1800 \mathrm{mg} / \mathrm{L}$. The linear equation was $\mathrm{y}=3540.6 \mathrm{x}-157151$ and correlation coefficient $\mathrm{r}^{2}$ was 0.9982 . According to the detection limit LOD $(\mathrm{S} / \mathrm{N} \geq 3$ ) and quantification limit $(\mathrm{S} / \mathrm{N} \geq 10$ ) (which were obtained by TGP mixed standard detection signal produced SNR calculation method), the LOD and LOQ for TGO was 28 and $113 \mathrm{mg} / \mathrm{L}$, respectively. The LOD and LOQ for TGD was 11 and $44 \mathrm{mg} / \mathrm{L}$. The LOD of TGP in oil was $0.01 \%$, as shown in Fig. 2a.

For ISO method, the whole oil was injected directly for HPSEC analysis. The non-polar triglycerides accounting for 70-97\% of oil attends the area normalization method in the RI detector ${ }^{17}$. This method was only suitable for fat samples of which the TGP content was higher than $3 \%^{11}$. When the preparative flash chromatography and HPSEC (PFC-HPSEC) method was used, the non-polar triglycerides which interfere normalization method for accurate quantification were preseparated. RI is quality detector and responds the same to all polar components. When the content of TGP in fat oil is lower than $3 \%$, more than $90 \%$ of non-polar triglycerides is pre removed, which is equal to that when the sample was concentrated 30 times and then use HPSEC area normalization method to quantify. Quantitative linear range is extended and meets TGP quantitative detection in low-TGP content of refined edible vegetable oil and squeezing edible vegetable oils ${ }^{8}$.

When TGP is determined by PFC-HPSEC, the key step is the separation effect of polar compounds with non-polar components in oil and the recovery of polar compounds containing TGP. The separation effect of polar compounds with non-polar 


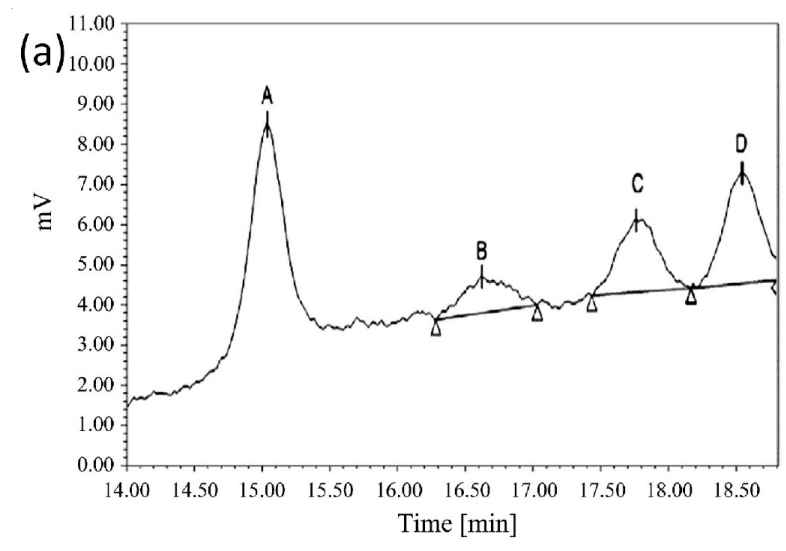

(b)
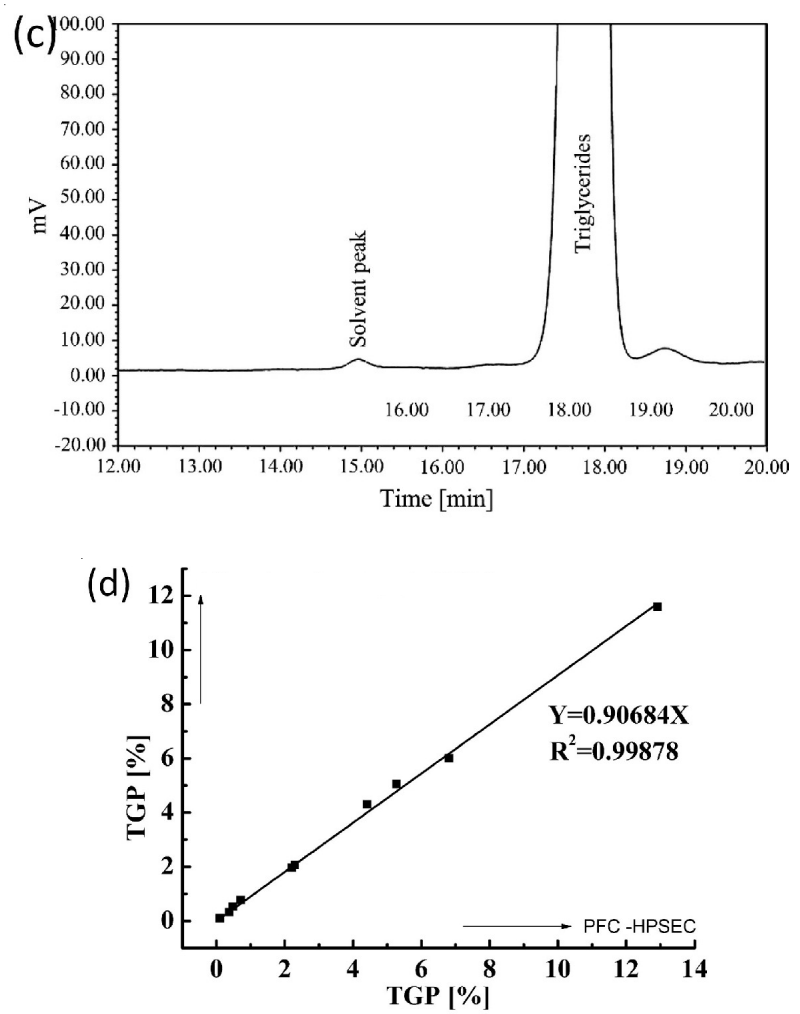

Fig. 2. (a) LOD of TGP by PFC-HPSEC. A: Solvent; B: TGD; C: ox-TGM; D: DG. (b) TLC evaluation of separation efficiency of polar fraction and non-polar fraction. 1: Nonpolar compounds, 2: Polar compounds. (c) HPSEC evaluation of separation efficiency by preparative flash chromatography separation. 1: Nonpolar compounds, 2: Polar compounds. (d) Correlation of \% TGP by PFC-HPSEC versus column chromatography-HPSEC

compounds by PFC was shown in Fig. 2b. The two components were separated completely via the examination of traditional
TLC. Even for at oil (eat hutch waste oil-5) with higher polar compounds content $(25 \%$, w/w), preparative flash column chromatography method could still completely separate polar compounds with non-polar compounds. Nonpolar components via HPSEC analysis authentication didn't contain any TGP and polar components and the results were depicted in Fig. 2c. If silica gel column was used, there would be 1-2 \% of the polar fractions from elution in grease samples with high content of polar compounds. Compared with that, the separation effect of polar compounds was better when using PFC method.

The cold-pressed sesame oil containing three concentration levels of polar compounds was added for recovery experiments. The recovery rate of polar compounds were all in the range of 95.4-97.7\%. Repeating determination 2 times, the relative standard deviation was less than $4 \%$. The results of recovery rate and precision determination were shown in Table-2.

\begin{tabular}{ccccc}
\multicolumn{5}{c}{ TABLE-2 } \\
\multicolumn{5}{c}{ RECOVERY AND PRECISION OF POLAR } \\
COMPOUNDS DETERMINATION BY PREPARATIVE \\
FLASH CHROMATOGRAPHY \\
\hline $\begin{array}{c}\text { Added } \\
(\mathrm{g} / \mathrm{L})\end{array}$ & $\begin{array}{c}\text { Found } \\
(\mathrm{g} / \mathrm{L})\end{array}$ & $\begin{array}{c}\text { Recovery } \\
(\%)\end{array}$ & $\begin{array}{c}\text { Mean recovery } \\
(\%)\end{array}$ & $\begin{array}{c}\text { RSD } \\
(\%)\end{array}$ \\
\hline 0.0233 & 0.0444 & 95.5 & 96.4 & 1.32 \\
0.0224 & 0.0437 & 97.3 & & 3.18 \\
\hline 0.0939 & 0.0938 & 99.9 & 97.7 & 1.41 \\
\hline 0.0916 & 0.0875 & 95.5 & 95.4 & \\
\hline 0.3618 & 0.1742 & 96.3 & 9 \\
0.3652 & 0.1732 & 94.4 & 9 & \\
\hline
\end{tabular}

Four concentration levels of edible vegetable oil and kitchen waste oil were selected and then injected 5 times under the best PFC-HPSEC conditions. The samples were soybean oil, kitchen oil-2, golden sun rice oil and kitchen waste oil-5. The relative standard deviations (RSD) of peak area of each sample were $7.58,8.52,9.50$ and $7.25 \%$, respectively. As shown in Table-3, these values were all lower than $10 \%$, which displayed the good repeatability of this method.

TABLE-3

REPEATABILITY OF TGP BY PFC-HPSEC

\begin{tabular}{|c|c|c|c|c|c|c|c|}
\hline \multirow{2}{*}{ Sample } & \multicolumn{5}{|c|}{ TGP content (\%) } & \multirow{2}{*}{$\begin{array}{c}\text { Average } \\
(\%)\end{array}$} & \multirow{2}{*}{$\begin{array}{l}\text { RSD } \\
(\%)\end{array}$} \\
\hline & 1 & 2 & 3 & 4 & 5 & & \\
\hline$\overline{\text { Soy }}$ & 0.40 & 0.38 & 0.43 & 0.35 & 0.38 & 0.39 & 7.58 \\
\hline $\begin{array}{r}\text { Used co } \\
\text { oil- }\end{array}$ & 2.59 & 2.48 & 2.41 & 2.30 & 2.76 & & 8.52 \\
\hline Rice bran oil & 0.11 & 4.74 & 5.4 & 5.47 & 5.07 & 5.3 & 9.50 \\
\hline $\begin{array}{c}\text { Used cooking } \\
\text { oil-5 } \\
\end{array}$ & 13.0 & 12.9 & 11.7 & 14.0 & 11.9 & 12.7 & 7.25 \\
\hline
\end{tabular}

Selecting the 10 meal kitchen waste grease blind sample provided by Ministry of Health, two operators in two different laboratories have detected the TGP content using different instruments, adopting the same PFC-HPSEC method as described earlier. As shown in Table-4, the relative standard deviations of TGP content were $6.48,8.57$ and $6.00 \%$, which were less than $10 \%$. Restricted by the number of domestic laboratory with related testing conditions, the limited comparison results preliminarily indicated that this method had a good reproducibility for quantifying TGP. 


\begin{tabular}{|c|c|c|c|}
\hline \multicolumn{4}{|c|}{$\begin{array}{c}\text { TABLE-4 } \\
\text { COMPARISON OF TGP DETECTED BY } \\
\text { PFC-HPSEC IN DIFFERENT LABORATORY }\end{array}$} \\
\hline Sample & TGP $(\%)$ & $\begin{array}{c}\text { Average TGP } \\
(\%)\end{array}$ & RSD (\%) \\
\hline M-1 & $\begin{array}{l}1.03 \\
1.13\end{array}$ & 1.08 & 6.48 \\
\hline M-2 & $\begin{array}{l}0.99 \\
1.11 \\
\end{array}$ & 1.05 & 8.57 \\
\hline M-3 & $\begin{array}{l}0.95 \\
1.04\end{array}$ & 1.00 & 6.00 \\
\hline M-4 & $\begin{array}{l}2.43 \\
2.38\end{array}$ & 2.40 & 1.67 \\
\hline M-5 & $\begin{array}{l}1.52 \\
1.36 \\
\end{array}$ & 1.44 & 8.33 \\
\hline M-6 & $\begin{array}{l}0.98 \\
1.09 \\
\end{array}$ & 1.04 & 7.69 \\
\hline M-7 & $\begin{array}{l}0.86 \\
0.84\end{array}$ & 0.85 & 1.18 \\
\hline M-8 & $\begin{array}{l}0.99 \\
1.07\end{array}$ & 1.03 & 5.83 \\
\hline M-9 & $\begin{array}{l}4.73 \\
4.87 \\
\end{array}$ & 4.80 & 2.08 \\
\hline M-10 & 1.13 & 1.14 & 0.88 \\
\hline
\end{tabular}

\begin{tabular}{lccc}
\multicolumn{4}{c}{ TABLE-5 } \\
\multicolumn{4}{c}{ COMPARATIVE DETERMINATION OF TGP $(\%)$} \\
\multicolumn{1}{c}{ IN OILS AND FATS OF DIFFERENT ORIGIN } \\
\hline \multicolumn{1}{c}{ Sample } & PFC-HPSEC & $\begin{array}{c}\text { Silica column } \\
\text { chromatography } \\
\text {-HPSEC }\end{array}$ & $\begin{array}{c}\text { RE } \\
(\%)\end{array}$ \\
\hline Soybean oil & 0.37 & 0.33 & 8.08 \\
Corn oil & 0.48 & 0.53 & 7.00 \\
Sunflower oil & 0.71 & 0.78 & 6.64 \\
Used cooking oil-1 & 2.21 & 1.97 & 8.12 \\
Used cooking oil-2 & 2.30 & 2.07 & 7.44 \\
Extra virgin olive & 0.10 & 0.10 & 0 \\
Used cooking oil-3 & 4.41 & 4.31 & 1.62 \\
Rice bran oil & 5.27 & 5.05 & 3.01 \\
Used cooking oil-4 & 6.81 & 6.00 & 8.94 \\
Used cooking oil-5 & 12.92 & 11.59 & 7.67 \\
\hline
\end{tabular}

HPSEC method reproduced well during the TGP determination in various oil samples compared with classical silica gel column chromatography-HPSEC method.

In addition to the total amount analysis of oil polar compounds, PFC-HPSEC method was also utilized to quantify TGP (TGO + TGD), ox-TGM, DG, FFA and polar unsaponifiable compounds within polar compounds. As shown in Table-6, the extra virgin olive oil (sample 6) contains no TGO. TGP content of refining and squeezing edible vegetable oil was rather low. TGP content of soybean oil, corn oil, sunflower oil and virgin olive oil was in the ranging of $0.1-0.86 \%$. But TGP content of refined rice oil (sample 8) was unusually higher, which should be due to the high oxidation of crude oil before the ubiquitous rice oil was refined. TGP content of refined kitchen waste oil (waste oil samples 1-5) was 3.3-25\%, which was significantly higher than that of edible vegetable oil.

\section{Conclusion}

A method via preparative PFC-HPSEC was set up for the quantitative determination of TGP content. This method also could be used to determine the ox-TGM, DG and other polar components within oil. Compared with the classic IUPAC standard method, this method is more simple and faster. The precision, accuracy and linear relationship of this method successfully meet with the requirement of qualitative and quantitative determination of TGP in pressing oils, refined oils, kitchen waste grease as well as other grease.

\section{ACKNOWLEDGEMENTS}

The work is supported by Key Projects in the National Science \& Technology Pillar Program during the Twelfth FiveYear Plan Period of China (Contract No: 2011BAD02B04), the National Natural Science Foundation of China (NSFC, 31171703) and Program for New Century Excellent Talents in University (NECT). The authors also thank the Testing \& Analysis Center of Jiangnan University.

The TGP contents of five edible vegetable oil and five meal kitchen waste oil samples were detected by using PFCHPSEC and IUPAC standard methods, respectively. The results were displayed in Table-5. The relative error (RE) of quantitative TGP by this method was in the range of $0-8.94 \%$. The correlation of two methods was shown in Fig. 2d. The correlation coefficient $\left(\mathrm{r}^{2}\right)$ and slope was 0.9979 and 0.9068 , respectively. This experiment clearly demonstrated that PFC-

\section{REFERENCES}

1. J. Velasco, S. Marmesat and M.C. Dobarganes, Chem. Frying, 33 (2008). 2. China Stand Method GB/T 5009.202 (2003).

3. DGF (German Society for Fat Research), Proceedings of the 3rd International Symposium of Deep-Fat Frying: Final Recommendations, Eur. J. Lipid Sci. Technol., 102, 594 (2002).

4. S. Marmesat, E. Rodrigues-Machado, J. Velasco and M. Dobarganes, Int. J. Food Sci. Technol., 42, 601 (2007).

TABLE-6 DISTRIBUTION OF POLAR COMPOUNDS IN OILS AND FATS OF DIFFERENT ORIGIN BY PFC-HPSEC $(\%)^{\mathrm{a}}$

\begin{tabular}{|c|c|c|c|c|c|c|c|}
\hline Sample & $\mathrm{PC}$ & TGP & TGO & TGD & ox-TGM & DG & FFA and unsaponifiables \\
\hline Soybean oil & 3.33 & 0.38 & 0.05 & 0.33 & 1.06 & 0.94 & 0.46 \\
\hline Corn oil & 4.91 & 0.51 & 0.10 & 0.41 & 0.77 & 2.54 & 0.49 \\
\hline Sunflower oil & 4.75 & 0.86 & 0.10 & 0.76 & 1.68 & 1.00 & 0.48 \\
\hline Used cooking oil-2 & 12.04 & 3.30 & 0.66 & 2.64 & 2.68 & 0.65 & 5.88 \\
\hline Extra virgin olive oil & 3.27 & 0.10 & $\mathrm{ND}^{\mathrm{b}}$ & 0.10 & 0.64 & 1.87 & 0.59 \\
\hline Used cooking oil-3 & 11.74 & 4.41 & 0.89 & 3.52 & 5.67 & 0.99 & 0.25 \\
\hline Used cooking oil-4 & 8.29 & 3.91 & 1.25 & 2.66 & 2.20 & 1.38 & 0.51 \\
\hline Used cooking oil-5 & 24.95 & 12.78 & 3.90 & 8.88 & 4.34 & 5.89 & 1.53 \\
\hline
\end{tabular}

${ }^{\mathrm{a}} \mathrm{n}=2 .{ }^{\mathrm{b}} \mathrm{ND}<0.01 \%$. 
5. M. Martín-Polvillo, G. Márquez-Ruiz and M.C. Dobarganes, J. Am. Oil Chem. Soc., 81, 577 (2004).

6. T. Gomes, D. Delcuratolo, V.M. Paradiso, C. Summo and F. Caponio, LWT-Food Sci. Technol., 44, 1236 (2011).

7. M.V. Ruiz-Méndez, G. Márquez-Ruiz and M.C. Dobarganes, Food Chem., 60, 549 (1997)

8. W.F. de Greyt, M.J. Kellens and A.D. Huyghebaert, Eur. J. Lipid Sci. Technol., 99, 287 (1997).

9. T. Gomes, J. Am. Oil Chem. Soc., 69, 1219 (1992).

10. W.M. Cao, B. Xue, W.G. Wang, F.X. Chen, W.D. Chen, Q.Z. Jin and X.G. Wang, China Oils Fats, 36, 57 (2011).

11. ISO Stand 16931 (2009).
12. AOCS Official Method Cd 22.

13. IUPAC Standard Method 2. 507 (1987))

14. IUPAC Standard Method 2. 508 (1992).

15. M.C. Dobarganes, M.C. Pérez-Camino and G. Márquez-Ruiz, Fat Sci. Technol., 90, 308 (1988).

16. M.C. Dobarganes, J. Velasco and A. Dieffenbacher, Pure Appl. Chem., 72, 1563 (2000).

17. G. Márquez-Ruiz, N. Jorge, M. Martín-Polvillo and M.C. Dobarganes, J. Chromatog. A, 749, 55 (1996).

18. J.D. Caldwell, B.S. Cooke and M.K. Greer, J. Am. Oil Chem. Soc., 88, 1669 (2011). 